\title{
La naturaleza como sujeto de derecho en Ecuador
}

\section{Nature as a subject of law in Ecuador}

\author{
Carmen Marina-Méndez \\ ut.carmenmmc56@uniandes.edu.ec \\ Universidad Regional Autónoma de los Andes, Tulcán \\ Ecuador \\ https://orcid.org/0000-0001-6386-3450 \\ Cristian Daniel Álvarez-Ceballos \\ dt.cristiandac60@uniandes.edu.ec \\ Universidad Regional Autónoma de los Andes, Tulcán \\ Ecuador \\ https://orcid.org/0000-0002-5729-5204
}

Recepción: 15 de septiembre 2021

Revisado: 25 octubre 2021

Aprobación: 15 de noviembre 2021

Publicación: 01 de diciembre 2021 


\section{Estimado Editor (a):}

La concepción epistémica, filosófica y moral con la que se establece a la naturaleza como un sujeto de derechos, parte desde la fundamentación subjetiva de paradigmas jurídicos, que dotan de intrínseco al ente natural para defender su integridad. Los nuevos dispositivos constitucionales están orientados a la consolidación de un nuevo modelo de comprensión respecto de la naturaleza como sujeto de derechos. Al ser la Naturaleza la fuente principal de los recursos para la subsistencia del ser humano esta debe ser protegida. (Pineda Reyes, y Vilela Pincay 2020). Al amparo de figuras jurídicas que se anteponen indispensables para obtener un medio ambiente sano y equilibrado.

En este sentido, la naturaleza es considerada una fuente inagotable de recursos exclusivos para los seres humanos, esta denominación autoritaria produce consecuencias nefastas para la biósfera. (Pinto, 2017). Ya que se debe procurar mantener un punto de equilibrio sin anteponer ningún tipo de intereses. La naturaleza en sí misma es una dimensión estructural equilibrada en constante dinamismo, de la cual la especie humana forma parte del balance reciproco con los demás seres vivos. (Pérez y Méndez, 2019). Esta evolución substancial debe conservarse en la medida en la que se le priorice a la naturaleza su valor subjetivo. Es fundamental el poder distinguir los derechos ambientales de los derechos Humanos o si estos son parte de los mismos, y que representan los Derechos de la Naturaleza individualmente para todos los seres vivos y para el planeta. (Martínez y Acosta, 2017). El saber identificar si estos derechos tienen un valor agregado o separado de los intereses sociales, es esencial para establecer la superioridad o la igualdad de los mismos. Existen razones fundamentales para que los ecocéntristas estén interesados en preservar la naturaleza no humana. Al haber encontrado un valor intrínseco en la naturaleza completamente independientemente del desarrollo integral de los seres humanos. (Torres, 2011). La importancia de sostener un ecosistema equilibrado radica en la integración directa de los seres humanos dentro de la naturaleza quien a través de sus acciones morales respaldan sus beneficios ecológicos. Estas corrientes de pensamiento en la narrativa constitucional del Ecuador continúan realizando 
importantes discusiones y polemizando en torno al ejercicio de los derechos de la naturaleza.

Por lo tanto, el Planeta Tierra, este super organismo impredecible y complicado susceptible de cuidados y mantenimiento, debe ser fortalecido y por lo tanto considerado como un sujeto de dignidad, portador de derechos. Porque todo lo que en él se alberga tiene un valor intrínseco, tenga o no una utilidad humana. (Martínez y Acosta, 2017). La perspectiva valorativa con que se define a la naturaleza como un sujeto de derechos más allá de su connotación jurídica. Contempla su independencia funcional como un ente capas de direccionarse así mismo, a través de una fuente estructural compleja, que incluye con ella a los seres humanos y a todas las especies vivientes. Siendo este un fundamento esencial para determinar su subjetividad y su valor eco céntrico. Esta atribución del derecho, convierte a la naturaleza en un ente jurídico sobre el cual se depositan características subjetivas que ante la inequidad es susceptible de reclamo. Una de las teorías que ha cobrado mayor relevancia para fortalecer los lazos que tienen las leyes jurídicas y las leyes naturales que rigen el universo trata sobre la Jurisprudencia de la Tierra la cual confiere derechos a todos los seres por el solo hecho de vivir y no por tener conciencia o moral.

Es evidente que las acciones administrativas del mundo son llevadas a cabo por el ser humano como el centro más dinámico por su capacidad de discernimiento y juicio. Es importante que otorgue un valor substancial al ecosistema que lo alberga ante ello una de las más grandes innovaciones del ecocentrismo es llevada a cabo por la Constitución Ecuatoriana al dotar a la naturaleza como un sujeto legítimo de derechos, es sin duda el mayor logro ecocéntrico alcanzado hasta la actualidad.

De allí que, la supervivencia natural otorga al ser humano la capacidad de ser el más apto para poder salvaguardar su integridad a tal punto que su creciente intelecto le ha permitido manipular todo lo que se mantiene a su alcance con el fin de lograr una mejor forma de vivir, creando así facultades ideológicas para la administración de su complejo sistema de pensamiento. Es importante captar que podemos hacer uso de los recursos naturales priorizando siempre que el medio ambiente se conserve y continúe con sus procesos evolutivos de manera equilibrada y armónica. El desarrollo 
humano ubica al individuo como el centro del desarrollo productivo más eficaz por lo que es conveniente potenciar sus capacidades a tal punto, que su inteligencia le permita elegir libremente entre las mejores opciones para salvaguardar su hábitat social y natural según sus necesidades e intereses

No existe un fundamento trascendental que indique la superioridad de los derechos de la naturaleza por sobre los de los seres humanos o viceversa, es evidente que para definir cada postulado existen diferencias notables que estructuran cada ideología pero que para establecer cada teoría existe un punto de convergencia que las mantiene unidas, de esta manera las características distintivas de cada doctrina dependen del grado valorativo ético y ontológico que sin ningún referente nos siguen llevando a la misma discusión. Útil únicamente para poder distinguir los posicionamientos que los debatientes en la ciencia jurídica siguen polemizando en la práctica y ejecución de dichos derechos, cabe destacar el planteamiento equitativo que los postula ambos como sujetos de dignidad, y desde este punto los dos toman ventaja en cuanto al valor intrínseco de sus derechos, pero que para la acción de cualquier postulado la diligencia de estas medidas serán siempre decididas por el ser humano, al ser un fin y un medio, directo o indirecto de todas las leyes adaptadas para conservar su valor substancial, de esta manera el antropocentrismo mantiene ventaja al haber creado al ecocentrismo para sus propios intereses. Ya que indiscutiblemente las normas acatadas para la prevención conservación y restauración del medio ambiente en la mayoría de los casos sirven para equiparar los daños ocasionados a los mismos seres humanos que se ven afectados por la destrucción de la naturaleza. Por otra parte, el postulado ecocéntrico debe aceptar que su axioma es promovido por el átropos y que el ser humano al ser parte fundamental de la naturaleza y como único defensor de sus derechos debe proponer medidas más radicales

A través del régimen de desarrollo. La Constitución del Ecuador quien es vanguardista en el progreso ecocéntrico, propone, mantener, conservar, recuperar y regenerar la naturaleza por la extracción equilibrada de sus recursos para solventar las necesidades de los seres humanos, teniendo en cuenta que es primordial mejorar las condiciones de vida de las personas, para garantizar su desarrollo. En tal sentido se 
consiente la apropiación de los recursos naturales en justa medida. Toda regla que surja a partir de los requerimientos para limitar ciertas conductas no puede prevenir la impunidad de los hechos. Esto demuestra que el alcance de los derechos de la naturaleza se acciona únicamente para el reclamo de los mismos, colocando como pasivo el postulado exocéntrico, toda vez que las teorías que fundamentan las bases planteadas son posiciones de pensamiento, argumentos que no pueden limitar las conductas pero que son aplicables al punto de establecer empates éticos. Por lo cual esta teoría debe seguir siendo reforzada, a tal punto que sea suficiente para poder justificar su apartado ontológico a través de las vías antropocéntricas., La narrativa doctrinaria planteada en los distintos cuerpos legales radica en encontrar diferentes planteamientos sobre un mismo objetivo, de esta manera ante una afirmación siempre va existir una contraposición. La elección de un planteamiento indica cual es la mejor alternativa sin embargo también es una opción encontrar un valor equitativo que promulgue la aceptación de ambas proposiciones bajo un valor convergente. Beneficiando siempre a la postura que aún se debe fortalecer.

Para finalizar, la contemplación analítica de estas dos teorías se limita a comprender la convergencia existente, para que las mismas puedan ser fortalecidas desde una complementación dicotómica. La ideología que complementa el reconocimiento subjetivo de la naturaleza es impulsada desde una óptica egocéntrica, la misma que fue propuesta por la previsión del ser humano bajo una fundamentación doctrinaria antropocéntrica. El estado biológico funcional de todos los seres es reconocido como natural. Desde esta perspectiva el ser antrópico sigue siendo parte integral de la naturaleza y por lo tanto la única vos de todos aquellos seres biológicos que no se pueden expresar La teoría egocéntrica la cual toma un valor emergente al ser un postulado que no tiene fuerza debe encontrar alternativas para limitar el paradigma antropocéntrico, la interrelación de estas posturas muy complejas deben seguir siendo tratadas sin intentar desacreditar a ninguna teoría, si no aceptar y trasmutar la convergencia existente entre las dos. 


\section{FINANCIAMIENTO}

No monetario.

\section{AGRADECIMIENTO}

A la Universidad Regional Autónoma de los Andes, Tulcán, por motivar el desarrollo de la Investigación.

\section{REFERENCIAS CONSULTADAS}

Asamblea Nacional Constituyente de la República del Ecuador, (2008). Constitución de la República del Ecuador. [Constitution of the Republic of Ecuador]. Montecristi. Registro Oficial 449 de 20-oct-2008. Recuperado de https://n9.cl/sia

Martínez, E. y Acosta, A. (2017). Los Derechos de la Naturaleza como puerta de entrada a otro mundo posible. [The Rights of Nature as a gateway to another possible world]. Direito e Práx., Rio de Janeiro, 8(4),2927-2961. DOI: $\underline{10.1590 / 2179-8966 / 2017 / 31220}$

Pérez, M. y Méndez, M. (2019). La dimensión naturaleza-cultura en la narrativa constitucional de Ecuador y Venezuela. [The nature-culture dimension in the constitutional narrative of Ecuador and Venezuela]. Revista digital de Ciencia, Tecnología e Innovación. 6, 1116-1128. Recuperado de: https://n9.cl/krwx8

Pineda Reyes, C., y Vilela Pincay, W. (2020). La naturaleza como sujeto de derecho en el ordenamiento jurídico ecuatoriano. [Nature as a subject of law in the Ecuadorian legal system]. Revista Universidad y Sociedad, 12(1), 217-224. Recuperado de: https://n9.cl/b0jzd

Pinto C. (2017). La naturaleza como sujeto de derechos: análisis bioético de las Constituciones de Ecuador y Bolivia. [Nature as a subject of rights: bioethical analysis of the Constitutions of Ecuador and Bolivia]. Revista Latinoamericana de Bioética, 18(1), 155-171, Doi: https://doi.org/10.18359/rlbi.3030.

Torres, C. (2011). Las versiones del desarrollo sostenible. [ Versions of sustainable development]. Sociedad e Cultura, Goiânia,14(1), 195-204. DOI: 10.5216/sec.v14i1.15703. 